\title{
Assessment of Wind Turbine Grid Connection Requirements in Turkey
}

\author{
M. E. HACIBEKİROĞLU, B. KEKEZOĞLU
}

\begin{abstract}
The use of distributed power generation systems in power systems is increasing day after day. Despite the contribution they make to the energy needs of these systems, they can also have adverse effects on the grid. Therefore, specific constraints are brought to the grid connection of the distributed energy systems and governments constitute legislations depending on their grids. In this study, available grid connection conditions for the wind turbines in Turkey have been presented and discussed by comparing these criteria with the similar ones around the world.
\end{abstract}

Keywords - wind power, power systems, grid connections criteria

\section{Introduction}

Due to the increase in energy needs which is parallel to the increase in the population of the world and environmental factors, wind energy power systems have been an important topic. Along with the increase in their use on the system, the analysis of the effects of wind turbines on power systems has become a necessity. Many countries established new special technical constraints to the grid connection of wind plants, especially to the ones that are connected to the transmission line. These technical limitations make the power systems affordable and safe and also keeps them always running. The regulations called as Grid-Code not only reduced the effects of wind turbines to the existing network systems but also has provided significant contributions to the turbine technology in terms of development [1]. Especially in the last decade as the number and the energy capacity of wind power plants in all of the countries increase, Grid-Code enforcements speed up [8].

In general, active and reactive power variations, frequency changes and the reactions that may occur during the system failure are taken into consideration. The governments determine national constrictions on each parameter by taking their grid statuses into account.

Many studies on the network connections of wind turbines was carried in literature. Some of these studies are summarized below. In the study held by Christiansen and Johnsen, Grid Codes of different countries were compared and analyzed in terms of static and dynamic decomposition [2].

Muhammed Emin HACIBEKIROĞLU

Necmettin Erbakan University

Turkey

Dr. Bedri KEKEZOĞLU

Yıldız Technical University

Turkey
Sourkounis et. al. studied the main criterion of the grid codes that are necessary for the integration of the wind energy systems to the network and examined their effects to the power systems in different European countries [3]. Gomes et. al. reviewed the Grid-Codes used in Brazil in recent years [4]. Gashi et. al. analyzed the grid-code requirements of Kosovo power system network [5].

This study tried to reveal the criteria used in Turkey about the network connections of wind turbines. These criteria were compared to the limit values used in the world and at the end of the study the criteria available was evaluated.

In the second section of this study, the limit values of wind turbines based on the reactive power control. In the third section the frequency shift, in the fourth section operating voltage range and in the fifth section the values related to the active power exchange were introduced. In the sixth section, the contributions of the turbines to the system following a failure was shown and the study was concluded with the last section.

\section{Reactive Power Control}

The production of reactive power in power systems contributes to the formation of stable voltage. Due to the increase in the contribution of wind energy to the networks, the wind plants must also provide the exchange of reactive power in the network. After the connection of the wind power plants to the grid, keeping the voltage changes within a certain range is a necessity. Reactive power must not be transmitted to very long distances. Therefore, power factor correction equipment must be provided within the regional network [8].

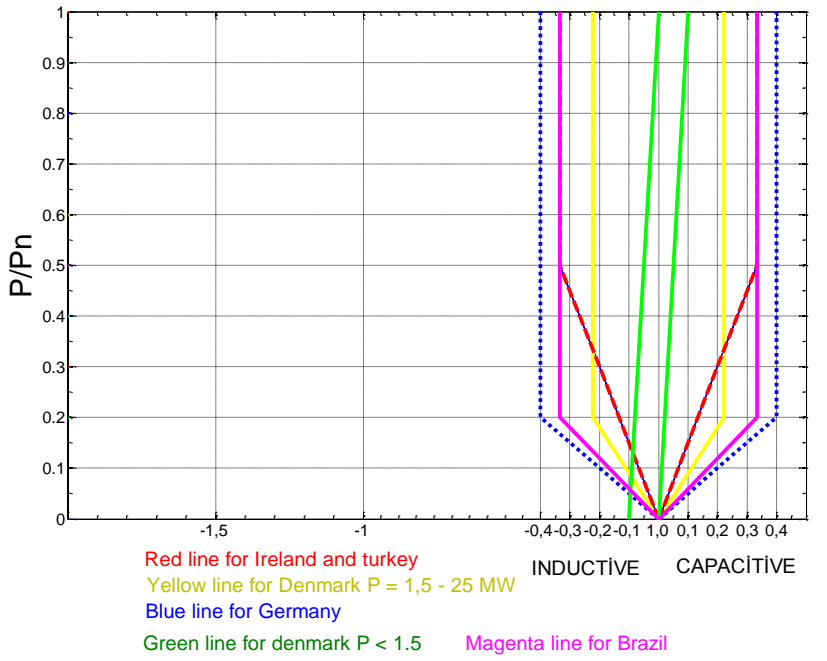

Figure 1. Reactive power curves of wind farms 
In Figure 1, the range of reactive power in wind turbines from different countries were shown. The most spacious working band exists in Germany. In Denmark however, for the wind turbines smaller than 1.5 MW power, reactive power exchange has been kept minimum. In Turkey, it is demanded that the power factor should be kept over 0.835 .

\section{Frequency Change}

The power systems must always have a balance between the production and the consumption of electricity. Any change in this balance changes the frequency and violate the frequency range which is defined previously defined within the network. The frequency deviation on the network would threaten the stability of the network and the security of the power system.

The generators used in the power systems were designed in such a way that they operate in a fixed frequency range. The Grid-Code's of the networks define the frequency range and the length of turbines' activity in case of a change in frequency. For different countries, the values depending on the change of frequency are shown in Table 1.

Table-I Frequency changes and generator working time of different countries.

\begin{tabular}{|c|c|c|}
\hline COUNTRY & Frequency Limit(Hz) & Maximum Time \\
\hline \multirow{6}{*}{ Turkey } & $51,5 \mathrm{~Hz} \leq \mathrm{f} \leq 52,5 \mathrm{~Hz}$ & 10 minute \\
\hline & $50,5 \mathrm{~Hz} \leq \mathrm{f}<51,5 \mathrm{~Hz}$ & 1 hour \\
\hline & $49 \mathrm{~Hz} \leq \mathrm{f}<50,5 \mathrm{~Hz}$ & Countinuous \\
\hline & $48,5 \mathrm{~Hz} \leq \mathrm{f}<49 \mathrm{~Hz}$ & 1 hour \\
\hline & $48 \mathrm{~Hz} \leq \mathrm{f}<48,5 \mathrm{~Hz}$ & 20 minute \\
\hline & $47,5 \mathrm{~Hz} \leq \mathrm{f}<48 \mathrm{~Hz}$ & 10 minute \\
\hline \multirow{4}{*}{ Germany } & $49 \mathrm{~Hz}<\mathrm{f}<50,5 \mathrm{~Hz}$ & Countinuous \\
\hline & $48,5 \mathrm{~Hz}<\mathrm{f}<51,5 \mathrm{~Hz}$ & 30 minute \\
\hline & $47,5 \mathrm{~Hz}<\mathrm{f}<51,5 \mathrm{~Hz}$ & 10 minute \\
\hline & $46,5 \mathrm{~Hz}<\mathrm{f}<51,5 \mathrm{~Hz}$ & 10 seconds \\
\hline \multirow{3}{*}{ Ireland } & $49 \mathrm{~Hz}<\mathrm{f}<50,5 \mathrm{~Hz}$ & Countinuous \\
\hline & $48,5 \mathrm{~Hz}<\mathrm{f}<51,5 \mathrm{~Hz}$ & 60 minute \\
\hline & $47,5 \mathrm{~Hz}<\mathrm{f}<51,5 \mathrm{~Hz}$ & 20 seconds \\
\hline \multirow{4}{*}{ Denmark } & $48,5 \mathrm{~Hz}<\mathrm{f}<51 \mathrm{~Hz}$ & Countinuous \\
\hline & $48 \mathrm{~Hz}<\mathrm{f}<51 \mathrm{~Hz}$ & 25 minute \\
\hline & $47,5 \mathrm{~Hz}<\mathrm{f}<52 \mathrm{~Hz}$ & 5 minute \\
\hline & $47 \mathrm{~Hz}<\mathrm{f}<52 \mathrm{~Hz}$ & 10 seconds \\
\hline
\end{tabular}

As seen in the table, the frequency ranges defined in the criteria differ from country to country. But wind power plants can operate permanently between $47.5 \mathrm{~Hz}$ to $52.5 \mathrm{~Hz}$ in four countries. While in Turkey the highest frequency value is defined as $52.5 \mathrm{~Hz}$, this value is determined as $51.5 \mathrm{~Hz}$ in Germany and Ireland, $52 \mathrm{~Hz}$ in Denmark. By contrast, the lowest frequency value allowed, $46.5 \mathrm{~Hz}$ is in Germany.

\section{Voltage Range}

In order to maintain the system healthy, the voltage can be changed within a given range. Voltage ranges in which wind turbines operate are shown below in Table 2 .

Table-II Allowed voltage ranges

\begin{tabular}{|c|c|}
\hline COUNTRY & Voltage Range \\
\hline \multirow{3}{*}{ Turkey } & $66 \mathrm{kV}$ from $-\% 10$ to $+\% 10$ \\
$154 \mathrm{kV}$ from $-\% 9$ to $+\% 11$ \\
$400 \mathrm{kV}$ from $-\% 15$ to $+\% 5$ \\
\hline \multirow{3}{*}{ Denmark } & $132 \mathrm{kV}$ from $-\% 5$ to $+\% 10$ \\
& $150 \mathrm{kV}$ from $-\% 3$ to $+\% 13$ \\
& $400 \mathrm{kV}$ from $-\% 10$ to $+\% 5$ \\
\hline Ireland & $110 \mathrm{kV}$ from $-\% 10$ to $+\% 12$ \\
& $220 \mathrm{kV}$ from $-\% 9$ to $+\% 12$ \\
& $400 \mathrm{kV}$ from $-\% 13$ to $+\% 8$ \\
\hline \multirow{5}{*}{ Germany } & $110 \mathrm{kV}$ from $-\% 13$ to $+\% 12$ \\
& $220 \mathrm{kV}$ from $-\% 13$ to $+\% 12$ \\
& $400 \mathrm{kV}$ from $-\% 8$ to $+\% 10$ \\
\hline
\end{tabular}

In the criteria of network connection, voltage range is defined separately for different voltage levels. As can be seen from Table 2, system operators of Denmark (TSO) can allow the voltage change to be between $-10 \%$ and $+13 \%$ regarding the size of the nominal voltage and the operation of wind power plants. Likewise if the allowed voltage changes in Ireland and Germany were considered, their values change between $-13 \%-+12 \%$. In Turkey, these values vary between $15 \%$ and $+11 \%$.

\section{v. Active Power Control}

Active power control is the ability of wind plants to control active power output on the determined level and rate. The purpose of this control is the maintenance of system frequency stability in case of an overload occurring in the transmission line or in bad weather conditions.

Depending on frequency, the changes in the active power outputs of wind plants belonging to different countries were shown in Figure 2. 
Proc. of the Second Intl. Conf. on Advances in Mechanical and Automation Engineering - MAE 2015

Copyright (C) Institute of Research Engineers and Doctors, USA .All rights reserved.

ISBN: 978-1-63248-045-3 doi: 10.15224/ 978-1-63248-045-3-45

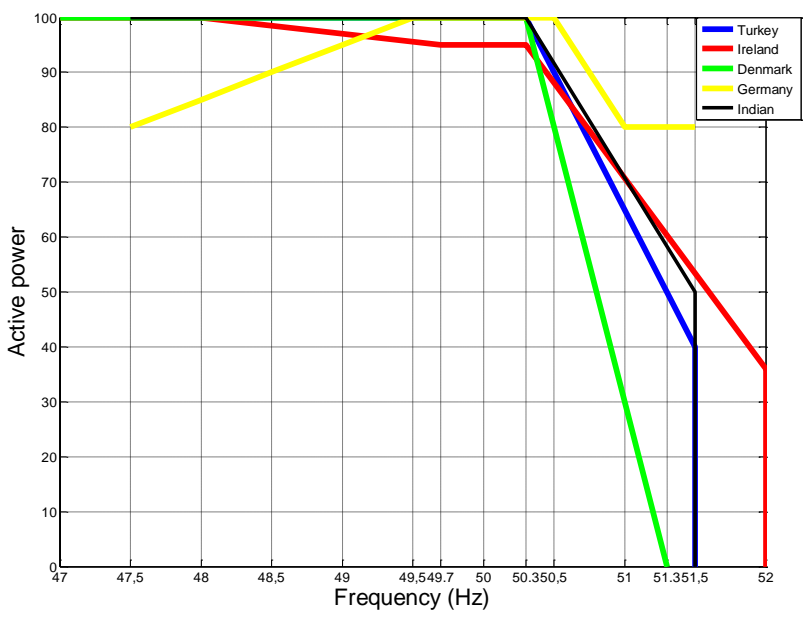

Figure 2. The changes in active power depending on frequency

As can be seen in the figure, when the active power frequency curve of wind turbines in Turkey was checked, it can be concluded that between 47,5 and $50.3 \mathrm{~Hz}$ the wind turbines can produce all the power required. If the frequency gets over $50.3 \mathrm{~Hz}$, then the wind plants should go to a $4 \%$ speed reduction and over the $51.5 \mathrm{~Hz}$, they should be disconnected. Similarly when the curve belonging to Denmark is analyzed, all of the nominal power can be produced between $47-50.3 \mathrm{~Hz}$ but wind plants have to be offline at $51.3 \mathrm{~Hz}$.

When the active power curve of Ireland was examined, it is seen that the level of the wind plants are like these: between $47-48 \mathrm{~Hz}$ frequencies all of the nominal power can be produced, between $49.7-50.3 \mathrm{~Hz}$ frequencies $95 \%$ of it can be produced and at $52 \mathrm{~Hz}$ they must be completely offline. When the same observation is done for Germany, nominal power can be produced completely between $49.5-50.5$ frequencies and at $51.5 \mathrm{~Hz}$ wind plants must go off.

The analysis done showed that the widest frequency range in which wind plants operate is present in Ireland. Additionally the country in which the maximum power that can be produced is Germany.

\section{vI. Fault Ride Through}

Any failure in anywhere of the power system can cause voltage drops in single or multiple phases. This type of voltage drop is seen in a specific time period depending on the ability of the network in clearing the failure.

The characteristics exhibited by high power wind turbines in case of a malfunction should be analyzed and evaluated regarding their effects to the system while they are being connected to the network.

Some failures in the networks can cause huge voltage drops and as a result this can make some generator units offline. In the years when the first regulations made in GridCode's, during system failures and in low voltages the wind turbines were allowed to be separated from the network, however in the regions where the contribution of wind plants to the network is high, separation of the wind plants from the network cause huge voltage drops and even can cause voltage collapse, for that reason nowadays these type of practices are not allowed. In other words, if voltage drop is a risk, then wind plants should be kept connected to the network [9].

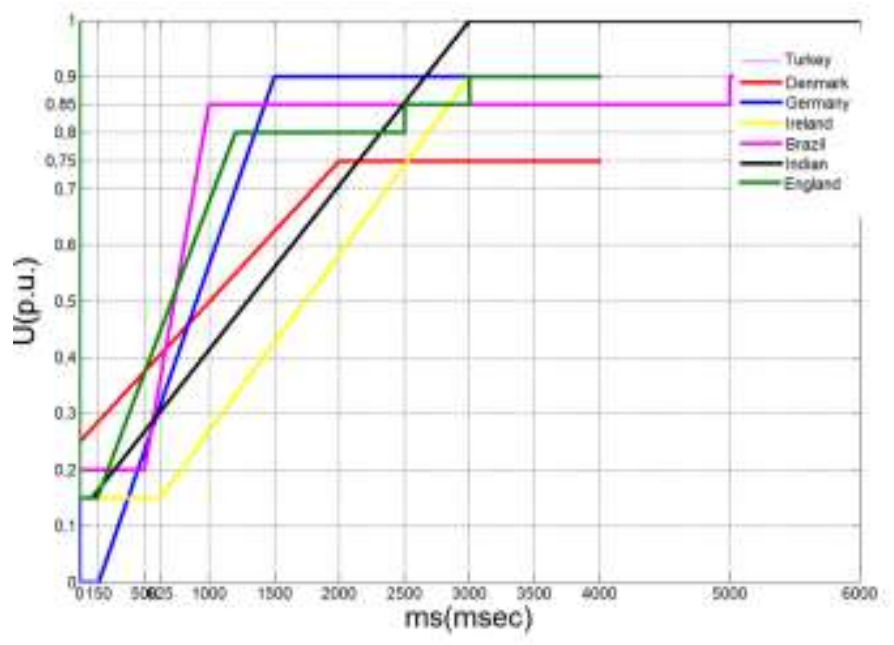

Figure 3. Fault ride through capability of wind farm power stations

In Figure 3, the time period of the network connections of wind plants in case of a failure are shown for Turkey, Denmark, Germany and Ireland respectively.

As can be seen in the graph, Ireland has the longest FRT (Fault Ride Through) time. Maximum time period required before the recovery of the voltage following a failure is 625 $\mathrm{ms}$ in Grid-Code's of Ireland. This value is $150 \mathrm{~ms}$ for Germany and Turkey, while it is $100 \mathrm{~ms}$ in Denmark.

The time that is required for recovering the voltage up to its normal levels after a failure is $2000 \mathrm{~ms}$ in Denmark, $3000 \mathrm{~ms}$ in Ireland, and $1500 \mathrm{~ms}$ both in Germany and in our country. After these durations, the voltage should rise up to $90 \%$ of nominal voltage in Turkey, Germany and Ireland, while it should be $75 \%$ in Denmark.

Failure to reach a certain level the voltage again after time in Denmark $2000 \mathrm{~ms}$, Ireland Germany and in our country in this time of $15003000 \mathrm{~ms}$ and ms per day. After this time, given the tension in Turkey, Germany and Ireland, 90\% nominal voltage in approximately $75 \%$ in Denmark to be reached.

Grid-Code's of Ireland has the highest time period regarding the FRT (Fault Ride Through) compared to the other countries.

\section{vII. Conclusion}

As the usage of wind turbines in power systems increased, the evaluation of their effects on the network has become indispensable and inevitable. So the governments established some constrictions about the network connections of turbines regarding their network connection statuses. 
This study reviewed the criteria of network connections in Turkey and compared these values to their counterparts in Ireland, Denmark and Germany. Accordingly,

- When the active power control regulations are checked, Denmark has the strictest regulations.

- Wind plants can operate between $47.552 .5 \mathrm{~Hz}$ frequency range in all countries. Considering the frequency changes, Denmark is the country where the transmission is least.

- Regarding the active power frequency change, the country which has the widest frequency range for the operation of wind plants is Ireland.

- The toughest regulations about the contribution of wind plants to the network in case of a failure belongs to Denmark is $100 \mathrm{~ms}$.

Nowadays the network structures constantly becomes sophisticated and new production units are being added onto the system. In this context, the criteria for network connection of wind turbines should be revised and adapted to the new conditions.

\section{Acknowledgment}

Authors would like thank to the Yildiz Technical University for full financial support of project namely "Investigation of Grid Code Requirements for Wind Farms ", Project No: 2015-04-02-YL01

\section{Referances}

[1] Lipnick, P., Jarzyna, W., ' Analysis of Grid Codes Requirements and Some Remarks to their Implementation for Wind Power Plants, VII Lubuska Conference Naukowo - Techninal - i - MITEL 2012.

[2] Willi Christiansen and David T. Johnsen, Analysis of requirements in selected Grid Codes, Qrsted DTU, Section of Electric power Engineering, Technical University of Denmark (DTU).

[3] C. Sourkounis and P. Tourou, 'Hindawi Publishing Corporation Conference Papers in Energy Volume 2013, Article ID 437674.

[4] Gomes, P., Martins, A., Zani, Cesar R., Sardinha, Sergio L. A., 'Connection Requirements and Grid Codes for Distributed Generation', IEEE Integration of Wide-Scale Renewable Resources Into The Power Delivery System, Calgary, Canada, July 29th-31st, 2009.

[5] A. Gashi, G. Kabashi, S. Kabashi, S. Ahmetaj, V. Veliu, Simulation the Wind Grid Code Requirements for Wind Farms Connection in Kosovo Transmission Grid, Energy and Power Engineering, 4, 482-495, 2012.

[6] Andrew Smith, 'Quantifying Exports and Minimizing Curtailment: From $20 \%$ to $50 \%$ Wind Penetration in Denmark', BIEE 2010.

[7] Fagan, E., Grimes, S., McArdle, J., Smith, P. and Stronge, M., ' Grid code provisions for wind generators in İreland', IEEE Power Engineering Society General Meeting, San Fransisco, vol. 2, pp. 1241-1247, 2005.

[8] Mansour Mohseni, Student Member, IEEE, and Syed M. Islam, Senior Member, IEEE.

[9] I. Erlich, W. Winter, and A. Dittrich, 'Advanced grid requirements for the integration of wind turbines into the German transmission system,' in Proceedings of the IEEE Power Engineering Society General Meeting (PES'06), p.7, June 2006. 